\title{
N-Acetylcysteine Suppresses Retinal Detachment in an Experimental Model of Proliferative Vitreoretinopathy
}

\author{
Hetian Lei, ${ }^{*}$ Gisela Velez, ${ }^{*}$ Jing Cui, ${ }^{\dagger}$ Arif Samad, ${ }^{\ddagger}$ \\ David Maberley, ${ }^{\dagger}$ Joanne Matsubara, ${ }^{\dagger}$ and \\ Andrius Kazlauskas*

\begin{abstract}
From the Department of Ophthalmology," Schepens Eye Research Institute, Harvard Medical School, Boston, Massachusetts; the Department of Ophthalmology and Visual Sciences, ${ }^{\dagger}$ University of British Columbia, Vancouver, British Columbia, Canada; and the Department of Ophthalmology, ${ }^{\ddagger}$ Dalhousie University,
\end{abstract} \\ Halifax, Nova Scotia, Canada
}

Proliferative vitreoretinopathy (PVR) is a complication that develops in $5 \%$ to $10 \%$ of patients who undergo surgery to correct a detached retina. The only treatment option for PVR is surgical intervention, which has a limited success rate that diminishes in patients with recurring PVR. Our recent studies revealed that antioxidants prevented intracellular signaling events that were essential for experimental PVR. The purpose of this study was to test whether $\mathrm{N}$-acetyl-cysteine (NAC), an antioxidant used in a variety of clinical settings, was capable of protecting rabbits from PVR. Vitreous-driven activation of PDGFR $\alpha$ and cellular responses intrinsic to PVR (contraction of collagen gels and cell proliferation) were blocked by concentrations of NAC that were well below the maximum tolerated dose. Furthermore, intravitreal injection of NAC effectively protected rabbits from developing retinal detachment, which is the sight-robbing phase of PVR. Finally, these observations with an animal model appear relevant to clinical PVR because NAC prevented human PVR vitreous-induced contraction of primary RPE cells derived from a human PVR membrane. Our observations demonstrate that antioxidants significantly inhibited experimental PVR, and suggest that antioxidants have the potential to function as a PVR prophylactic in patients undergoing retinal surgery to repair a detached retina. (Am J Patbol 2010, 177:132-140; DOI: 10.2353/ajpath.2010.090604)
Proliferative vitreoretinopathy (PVR) is a complication that develops in a patient undergoing surgery to correct a detached retina. ${ }^{1,2}$ Cells that are mislocalized to the vitreous proliferate, synthesize extracellular matrix proteins and organize into an epiretinal membrane. The most sight-robbing phase of PVR occurs when the membrane contracts and detaches the retina.

Although only a minority (5\% to $10 \%$ ) of patients who undergo retinal re-attachment surgery develop PVR, the only treatment involves removing the epiretinal membrane surgically. ${ }^{1-3}$ The percentage of these first-time PVR patients who fail to achieve anatomical success is $20 \%$ to $40 \%$, and such patients are more prone to experience additional bouts of PVR. ${ }^{1,4,5}$ Thus the available treatment option for PVR is not ideal.

There have been multiple attempts to develop nonsurgical therapies for PVR. These include pharmacological strategies to block the cellular events intrinsic to PVR. For instance, investigators have tried using antiproliferative agents to prevent PVR such as 5-fluorouracil ${ }^{6}$ and daunomycin $^{7,8}$ that are used to treat patients with cancer. Although these approaches have shown some success in either animal models or limited clinical applications, they have not been found to be widely successful. ${ }^{9-12} \mathrm{~A}$ recent study in a small number of patients indicates that postoperative oral 13-cis-retinoic acid treatment was beneficial for maintaining retinal attachment, decreasing macular pucker, and improving vision. ${ }^{13}$

A fundamental understanding of the biochemical/molecular events that drive key processes intrinsic to a disease has been instrumental in developing effective therapies. For instance, the discovery that vascular endothelial growth factor is one of the potent drivers of angiogenesis guided development of anti-angiogenic

Supported by NIH grant EY012509 to A.K., and Canadian Institutes of Health Research to J.M.

Accepted for publication March 15, 2010.

Supplemental material for this article can be found on http://ajp. amjpathol.org

Address reprint requests to Andrius Kazlauskas, Ph.D., Schepens Eye Research Institute, Harvard Medical School, 20 Staniford St, Boston, MA 02114. E-mail: ak@eri.harvard.edu. 
therapies that are widely used to improve vision and/or delay vision loss in patients with the wet (neovascular) form of age-related macular degeneration. ${ }^{14}$ Similarly, identification of an activated tyrosine kinase as the genetic lesion underlying chronic myelogenous leukemia directed efforts to develop kinase inhibitors (Imatinib mesylate and related compounds) that are currently used to extend the life-expectancy of a substantial percentage of individuals afflicted with this disease. ${ }^{15}$

There is a growing appreciation that growth factors in the vitreous are likely to be driving the cellular events intrinsic to PVR. For instance, members of the plateletderived growth factor (PDGF) family are present at high levels in the vitreous of the vast majority of PVR patients, whereas only a small minority of patients with retinal issues unrelated to PVR has a detectable level of PDGFs in their vitreous. ${ }^{16}$ Furthermore, cells within epiretinal membranes obtained from patients with PVR express PDGF receptors (PDGFRs) and these receptors are activated. ${ }^{17}$

A rabbit model of PVR that models the sight-robbing retinal detachment phase of $P V R$ reflects a number of features of clinical PVR including high levels of PDGFs in the vitreous and a suspected role for PDGFRs in cells that form the epiretinal membrane. ${ }^{16,18-20}$ Experiments designed to test the importance of PDGFR activation for disease progression led to a number of surprising discoveries. Although activation of PDGFR was essential for experimental PVR, direct activation by PDGF was dispensable. ${ }^{17-19}$ Instead, indirect activation of PDGFR triggered signaling events leading to PVR. ${ }^{17,21}$ Indirect activation of PDGFR is a relatively obscure phenomenon, which proceeds as follows. Vitreal growth factors outside of the PDGF family activate their own receptors and thereby increase the intracellular concentration of reactive oxygen species (ROS), which activate Src family kinases that lead to activation of PDGFR. ${ }^{21}$

These studies identified a number of potential therapeutic targets. For instance, antioxidants such as $\mathrm{N}$-acetylcysteine (NAC) prevent the accumulation of ROS, and thereby block indirect activation of PDGFR and cellular events intrinsic to PVR. ${ }^{21}$ NAC is a safe and inexpensive compound that is currently used in a variety of clinical applications. Consequently, we tested if intravitreal injection of NAC would protect rabbits from undergoing retinal detachment in our PVR model.

\section{Materials and Methods}

\section{Cell Culture}

F cells are mouse embryo fibroblasts derived from mice deficient for pdgfra and pdgfrb genes that were immortalized with SV40 large T antigen. ${ }^{18} \mathrm{~F} \alpha \Delta \mathrm{x}$ cells are $\mathrm{F}$ cells engineered to express a mutant human $\operatorname{PDGFR} \alpha$ without the extracellular domain. ${ }^{21} \mathrm{~F} 31 / 42$ cells are $\mathrm{F}$ cells expressing a PDGFR $\alpha$ mutant in which tyr at 731 and 742 are mutated to phe. ${ }^{22}$ ARPE19 (RPE19) cells are a human retinal pigment epithelial cell line purchased from American Type Culture Collection (Manassas, VA). Primary rabbit conjunctiva fibroblasts (RCF) were isolated from rabbit conjunctiva as previously described. ${ }^{23}$ RPE $19 \alpha$ cells were generated by expressing human PDGFR $\alpha$ in the parental RPE19 cells. ${ }^{16}$

To obtain cells from a PVR membrane, a single epiretinal membrane from a patient with a retinal detachment and PVR was surgically removed and placed in Ham's F12 medium (Gibco BRL, Grand Island, NY). The membrane was washed with Hanks' balanced salt solution, dissected into $0.3 \mathrm{~cm} \times 0.3 \mathrm{~cm}$ pieces, and placed into separate $35-\mathrm{mm}$ culture dishes containing Ham's F12 medium, 30\% fetal bovine serum (FBS; Gibco BRL), penicillin G sodium (100 units $/ \mathrm{ml}$ ), and streptomycin (100 $\mathrm{mg} / \mathrm{ml}$ ). After cells migrated out of the explants, the cells were dissociated with $0.25 \%$ trypsin (Gibco BRL) and placed into culture dishes containing growth medium (Ham's F12 plus 10\% FBS and antibiotics as described above). Characterization of the resulting cells indicated that they stained positively for cytokeratin but weakly for $\alpha$-smooth muscle actin. ${ }^{24}$

RCF, F, F31/42, and $F \alpha \Delta x$ cells were maintained in Dulbecco's modified Eagle's medium (DMEM; high glucose; Gibco BRL) supplemented with 10\% FBS, $500 \mathrm{U} / \mathrm{ml}$ of penicillin, and $500 \mu \mathrm{g} / \mathrm{ml}$ of streptomycin. RPE and RPE $19 \alpha$ cells were cultured in a 1:1 mixture of DMEM and Ham's F12 medium (Gibco BRL) supplemented with 10\% FBS, $500 \mathrm{U} / \mathrm{ml}$ of penicillin, and $500 \mu \mathrm{g} / \mathrm{ml}$ of streptomycin. All cells were cultured at $37^{\circ} \mathrm{C}$ in a humidified $5 \%$ $\mathrm{CO}_{2}$ atmosphere.

\section{Major Reagents}

The anti-PDGFR $\alpha$ antibody (27P) was produced and characterized as previously described. ${ }^{25}$ The antiphosphotyrosine antibodies, 4G10 and PY20, were purchased from Upstate and BD Transduction Laboratories (Madison, WI), respectively. For some experiments, we used a commercially available anti-PDGFR $\alpha$ antibody number 3164 from Cell Signaling (Beverly, MA). The phospho-Y742 PDGFR $\alpha$ antibody was raised against the following phospho-peptide (KQADTTQY [Phospho-Y742] VPMLDMK) that was synthesized by Tufts Medical School (Boston, MA). Rabbits were immunized with this peptide by $\alpha$ Diagnostic International, Inc. (San Antonio, TX) by using the standard immunization protocol. Recombinant mouse basic fibroblast growth factor (bFGF) was purchased from Peprotech Inc. (Rocky Hill, NJ). Antibodies that recognized horseradish peroxidase-conjugated goat anti-rabbit IgG, and goat anti-mouse IgG secondary antibodies, were purchased from Santa Cruz Biotechnology (Santa Cruz, CA). Enhanced chemiluminescent substrate for detection of horseradish peroxidase was from Pierce Protein Research Products (Rockford, IL). NAC was purchased from Sigma (St. Louis, MO).

\section{Measurement of ROS Production}

Intracellular $\mathrm{H}_{2} \mathrm{O}_{2}$ generation was measured indirectly by using the fluorescent dye, $2^{\prime}, 7^{\prime}$-dichlorofluorescein diacetate, as described previously. ${ }^{21}$ Briefly, serum-deprived 
F $\alpha \Delta x$ cells were stimulated for 10 minutes with bFGF ( 100 $\mathrm{ng} / \mathrm{ml}$ ) or PVR rabbit vitreous. Subsequently, the cells were rinsed twice with Krebs-Ringer solution and incubated in Krebs-Ringer solution containing $2^{\prime}, 7^{\prime}$-dichlorofluorescein diacetate $(5 \mu \mathrm{mol} / \mathrm{L})$. In the presence of $\mathrm{H}_{2} \mathrm{O}_{2}, 2^{\prime}, 7^{\prime}$ dichlorofluorescein diacetate is oxidized to the highly fluorescent 2',7'-dichlorofluorescein. Culture dishes were sealed with paraffin film and placed in a $\mathrm{CO}_{2}$ incubator at $37^{\circ} \mathrm{C}$ for 5 minutes, after which $2^{\prime}, 7^{\prime}$-dichlorofluorescein fluorescence was read with a Bio-Tek fluorescence plate reader at excitation and emission wavelengths of 485 and $528 \mathrm{~nm}$, respectively.

\section{Immunoprecipitation and Western Blot}

Cells were grown to $90 \%$ confluence and then incubated for 24 hours in the medium without serum. The cells were pretreated with $\operatorname{NAC}(0.1,0.5$, and $2.5 \mathrm{mmol} / \mathrm{L})$ for 10 minutes and then exposed to bFGF $(100 \mathrm{ng} / \mathrm{ml})$ or rabbit vitreous (diluted 1:2 in DMEM) for 10 minutes. After washing twice with ice-cold PBS, the cells were lysed in extraction buffer $(10 \mathrm{mmol} / \mathrm{L}$ Tris- $\mathrm{HCl}, \mathrm{pH} 7.4,5 \mathrm{mmol} / \mathrm{L}$ EDTA, $50 \mathrm{mmol} / \mathrm{L} \mathrm{NaCl}, 50 \mathrm{mmol} / \mathrm{L} \mathrm{NaF}, 1 \%$ Triton X-100, $20 \mu \mathrm{g} / \mathrm{ml}$ aprotinin, $2 \mathrm{mmol} / \mathrm{L} \mathrm{Na}_{3} \mathrm{VO}_{4}$, and $1 \mathrm{mmol} / \mathrm{L}$ phenylmethylsulfonyl fluoride). Lysates were centrifuged for 15 minutes at $13,000 \times g, 4^{\circ} \mathrm{C}$, and PDGFR $\alpha$ was immunoprecipitated from clarified lysate as previously described. ${ }^{21}$ The immunoprecipitating antibody was a crude rabbit polyclonal (27P), which recognized the cytosolic domain of PDGFR $\alpha$. The blotting antibody was a 1:1 mixture of antiphosphotyrosine antibodies (4G10/ PY20). The membrane was stripped and reprobed with the PDGFR $\alpha$ antibody. Signal intensity was determined by densitometry by using Quantity One (Bio-Rad, Hercules, CA) and normalized for the amount of PDGFR $\alpha$ in each sample. ${ }^{21}$

PVR membranes isolated from rabbits were pooled and homogenized in sample buffer (10 mmol/L EDTA, 2\% SDS, $50 \mathrm{mmol} / \mathrm{L}$ Tris- $\mathrm{HCl}[\mathrm{pH}=6.8], 10 \%$ glycerol, $1 \%$ $\beta$-mercaptoethanol, and $0.02 \%$ bromophenol blue). The samples were subjected to Western blotting using a phospho-Y742 PDGFR $\alpha$ antibody. The blot was subsequently stripped and reprobed with an antibody against PDGFR $\alpha$.

\section{Cell Proliferation Assay}

Cells ( $F, F \alpha \Delta x, R C F$, and RPE $19 \alpha$ ) were seeded into a 24-well plate at a density of $3 \times 10^{4}$ cells/well in DMEM and $10 \%$ FBS. After 8 hours, the cells had attached, the medium was aspirated, and the cells were rinsed twice with PBS and $0.5 \mathrm{ml}$ of serum-free DMEM or rabbit vitreous (diluted 1:2 in DMEM) \pm NAC (10, 20, or $50 \mathrm{mmol} / \mathrm{L})$ was added. The media were replaced every day. The cells were counted in a hemocytometer on day 7 . Each experimental condition was assayed in duplicate, and at least three independent experiments were performed.

\section{Replating Assay}

$\mathrm{F} \alpha \Delta \mathrm{x}, \mathrm{RCF}$, and RPE $19 \alpha$ cells were treated with NAC (O, $10,20$, or $50 \mathrm{mmol} / \mathrm{L})$ for 7 days, counted as described above and replated into a new 24-well plate. After incubation for 6 hours, the adherent cells were enzymatically released from the dish and recounted by using a hemocytometer; at least three independent experiments were performed.

\section{Collagen I Contraction Assay}

$\mathrm{F}, \mathrm{F} \alpha \Delta \mathrm{x}$, or primary human RPE cells isolated from an epiretinal membrane were suspended in $1.5 \mathrm{mg} / \mathrm{ml}$ of neutralized collagen I (INAMED, Fremont, $\mathrm{CA} ; \mathrm{pH} 7.2$ ) at a density of $10^{6}$ cells $/ \mathrm{ml}{ }^{17,20}$ The cells/collagen mixture was transferred into a 24-well plate that had been preincubated overnight with $5 \mathrm{mg} / \mathrm{ml}$ bovine serum albumin in PBS. The collagen was solidified by incubating at $37^{\circ} \mathrm{C}$ for 90 minutes, and then $0.5 \mathrm{ml}$ DMEM or rabbit vitreous (diluted $1: 2$ in DMEM) \pm NAC $(10 \mathrm{mmol} / \mathrm{L})$ was added. The media were replaced every day. The gel diameter was measured on days $1,2,3$, and 4 . The area was calculated by using the formula $\pi r 2$, where $r$ is the radius of the gel. Each experimental condition was assayed in duplicate, and at least three independent experiments were performed.

\section{Rabbit Model for PVR}

PVR was induced in the right eyes of pigmented rabbits purchased from Covance (Denver, PA) as previously described..$^{18}$ Briefly, a gas vitrectomy was performed by injecting $0.1 \mathrm{ml}$ of perfluoropropane $\left(\mathrm{C}_{3} \mathrm{~F}_{8}\right.$; Alcon, Fort Worth, TX) into the vitreous cavity $4 \mathrm{~mm}$ posterior to the corneal limbus. One week later, all rabbits received two injections: (1) $0.1 \mathrm{ml}$ of platelet-rich plasma and (2) $0.1 \mathrm{ml}$ DMEM containing $2 \times 10^{5} \mathrm{~F} \alpha \Delta \mathrm{X}$ cells. All rabbits underwent a third injection consisting of $0.1 \mathrm{ml}$ of either 100 $\mathrm{mmol} / \mathrm{L}$ NAC in DMEM, or DMEM alone. The NAC or DMEM injection was repeated on days 2,4 , and 7 . The retinal status was evaluated with an indirect ophthalmoscope fitted with a +30 D fundus lens (Volk Optical, Inc., Mentor, $\mathrm{OH}$ ) at days 1, 3, 5, 7, 14, 21, and 28. PVR was graded according to the Fastenberg classification from 0 to 5 . On day 28 the animals were sacrificed, the eyes were enucleated and either frozen at $-80^{\circ} \mathrm{C}$, or placed on ice and dissected to recover the PVR membrane. All surgeries were performed under aseptic conditions and pursuant to the Association for Research in Vision and Ophthalmology (ARVO) Statement for the Use of Animals in Ophthalmic and Vision Research. The protocol for the use of animals was approved by the Schepens Animal Care and Use Committee.

\section{Preparation of Rabbit Vitreous}

Rabbit vitreous was prepared as follows. The vitreous was dissected from frozen rabbit eyeballs, allowed to thaw, and then centrifuged for 5 minutes at $4^{\circ} \mathrm{C}, 10,000 \times$ 
g. The resulting supernatant was used for all analyses. The eyes were not manipulated in any way and were normal and free of obvious abnormalities.

\section{Patient Vitreous}

Ethical approval was obtained before the initiation of this project from the Vancouver Hospital and University of British Columbia Clinical Research Ethics Board. The University of British Columbia Clinical Research Ethics Board policies comply with the Tri Council Policy and the Good Clinical Practice Guidelines, which have their origins in the ethical principles in the Declaration of Helsinki. Written informed consent was obtained from patients.

Vitreous humor samples were obtained during pars plana vitrectomy performed on five patients with PVR. Samples from patients who had previously undergone vitrectomy were excluded from this study. All subjects underwent a standard three-port vitrectomy, with a core sample of vitreous (1.0 to $1.5 \mathrm{ml}$ ) taken before initiating the pars plana infusion as described previously. ${ }^{26}$ Undiluted samples were divided into aliquots and stored at $-80^{\circ} \mathrm{C}$ until use.

\section{Statistics}

The experimental data were analyzed using an unpaired $t$-test or a Mann Whitney test. A $P$ value less than 0.05 was considered statistically significant.

\section{Results}

\section{Establishment of the Minimal and Maximal NAC Dose}

The first step in testing if antioxidants could protect rabbits from experimental PVR was to determine the minimal dose of a suitable anti-oxidant that prevented vitreousdriven biochemical and cellular events intrinsic to PVR. We focused on NAC because it is safe and effective in several clinical settings such as mucolytic therapy (Mucomyst, Mucosil) and treatment of acetaminophen overdose (Parvole, Acetadote). As shown in Figure 1, A and $B$, pretreating cells with concentrations of NAC greater or equal to $0.5 \mathrm{mmol} / \mathrm{L}$ prevented a rise in the level of ROS and activation of PDGFR $\alpha$ by either bFGF (a representative vitreal growth factor) or vitreous. The observation that millimolar concentrations of NAC were effective was consistent with the reports from several laboratories. ${ }^{21,27,28}$ The concordance between ROS production and activation of PDGFR $\alpha$ supports our previous findings that growth factors outside of the PDGF family engage a ROS-dependent mechanism to indirectly activate PDGFR $\alpha{ }^{21}$

We also determined the maximum tolerated dose of NAC in several cell types relevant to experimental PVR, including human RPE cells (RPE19 $\alpha$ ), RCFs, and F cells expressing a truncated PDGFR $\alpha$ mutant that can only be activated indirectly $(F \alpha \Delta x)$. The cells were cultured in
A

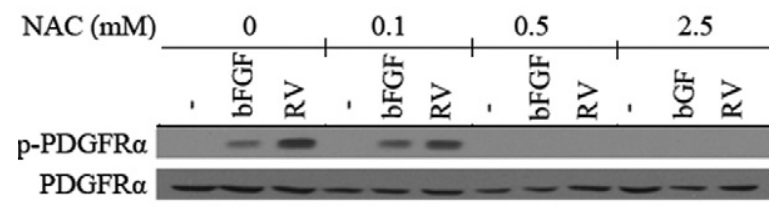

Fold: $\begin{array}{lllllllllllll}1.0 & 3.6 & 7.5 & 1.0 & 2.8 & 5.3 & 1.0 & 1.0 & 1.0 & 1.0 & 1.0 & 1.0\end{array}$

\section{B}

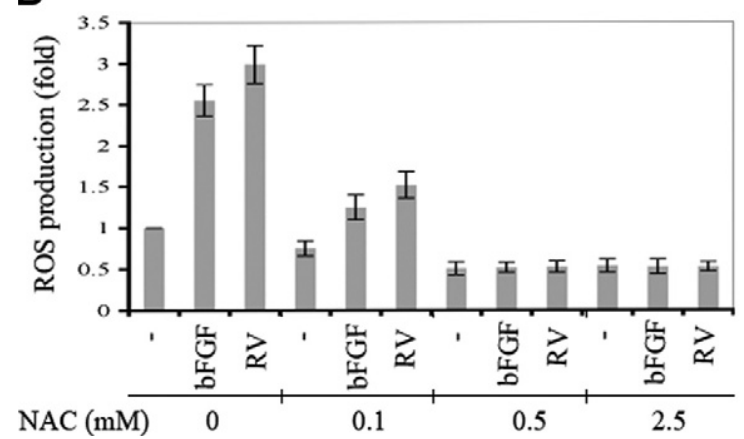

Figure 1. NAC prevented indirect activation of PDGFR $\alpha$ by rabbit vitreous and bFGF. A: Near confluent $\mathrm{F} \alpha \Delta \mathrm{x}$ cells were serum-starved for 24 hours, pretreated with NAC $(0,0.1,0.5$, and $2.5 \mathrm{mmol} / \mathrm{L})$ for 10 minutes, and then nothing (-), bFGF $(100 \mathrm{ng} / \mathrm{ml})$, or $1.5 \mathrm{ml}$ of vitreous (RV) isolated from healthy rabbits (diluted 1:2 in DMEM) was added and incubated for ten minutes at $37^{\circ} \mathrm{C}$. The cells were lysed, and PDGFR $\alpha$ was immunoprecipitated using an anti-PDGFR $\alpha$ (27P) antibody. The resulting samples were analyzed by sequential Western blotting: first, with a mixture of antiphosphotyrosine antibodies (pY20 and 4G10; top panel); second, with an anti-panPDGFR $\alpha$ antibody (27P; bottom panel). The intensity of the p-PDGFR $\alpha$ bands was normalized by the intensity of the corresponding PDGFR $\alpha$ bands; the ratio of these two values is shown at the bottom of the panel. The average fold change in three independent experiments was $3.5 \pm 0.3$ and $6.9 \pm 0.6$ for bFGF and rabbit vitreous, respectively. The results indicate that a 10 -minute pre-incubation with $0.5 \mathrm{mmol} / \mathrm{L}$ or greater NAC was sufficient to prevent activation of PDGFR $\alpha$ by either a single representative vitreal growth factor (bFGF) or the combination of all growth factors present in the vitreous. B: $\mathrm{F} \alpha \Delta \mathrm{x}$ cells treated as described in $\mathbf{A}$ were washed with Krebs-Ringer solution twice and then incubated with $2^{\prime}, 7^{\prime}$ dichlorofluorescein $(5 \mu \mathrm{mol} / \mathrm{L})$ for 5 minutes at $37^{\circ} \mathrm{C}$. The cells were then placed in a Bio-Tek fluorescence plate reader (excitation and emission wavelengths of 485 and $528 \mathrm{~nm}$, respectively). The results in this figure are from three independent experiments; the bars represent the mean, whereas the error bars indicate the SD. bFGF and RV increased the level of ROS, and this event was suppressed by pretreating cells with a dose of NAC that was equal to or greater than $0.5 \mathrm{mmol} / \mathrm{L}$.

complete growth culture medium supplemented with increasing concentrations of NAC. The medium was refreshed daily, and on day 7 the cells were photographed (Figure 2A shows representative photos) and counted (Figure 2B). As the concentration of NAC was increased, the proliferative capacity declined, such that all three cell types achieved a lower cell density. In the presence of 50 $\mathrm{mmol} / \mathrm{L}$ NAC, cells were unable to proliferate and developed abnormalities such as nuclear condensation (Figure 2A). Furthermore, on trypsinization and replating, the vast majority of cells treated in 10 or $20 \mathrm{mmol} / \mathrm{L}$ NAC re-attached, whereas less than $10 \%$ of cells cultured in the presence of $50 \mathrm{mmol} / \mathrm{L} \mathrm{NAC}$ were capable of reattaching (Figure 2C). Taken together, these data indicate that the three cell types behaved comparably, and although proliferation was reduced as the concentration of NAC was increased, cells appeared viable provided that the concentration of NAC was kept equal to or below $20 \mathrm{mmol} / \mathrm{L}$. 
A
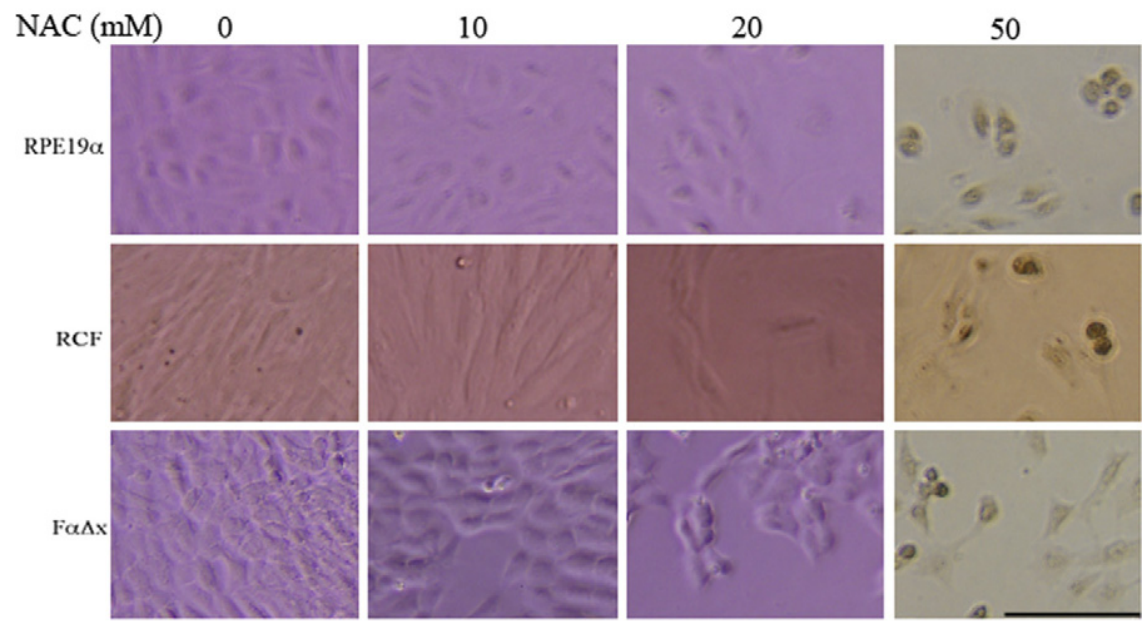

B

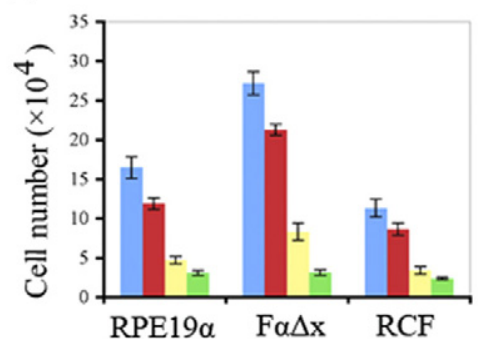

C

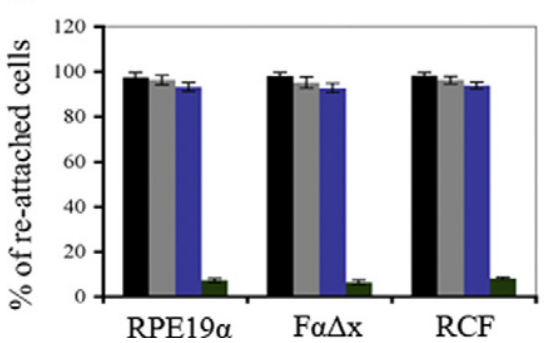

Figure 2. Establishment of the maximum-tolerated dose of NAC for cultured cells. A: RPE19 $\alpha$, $\mathrm{RCF}$, and $\mathrm{F} \alpha \Delta \mathrm{x}$ cells were plated in complete growth medium at $3 \times 10^{4}$ cells/well of a 24 -well plate. Within 24 hours, the indicated concentration of NAC was added. The media were refreshed daily, and the experiment was continued for a total of seven days. The pictures shown were taken on day seven. In the presence of 50 $\mathrm{mmol} / \mathrm{L}$ NAC, nuclear condensation developed in all three cell types. Scale bar $=100 \mu \mathrm{m}$. B: The cells described in $\mathbf{A}$ were counted on day seven, and the data (cell numbers) from three independent experiments were graphed (the mean $\pm \mathrm{SD}$ ). Blue, red, yellow, and green correspond to $0,10,20$, and $50 \mathrm{mmol} / \mathrm{L} \mathrm{NAC}$, respectively. C: The cells described in $\mathbf{B}$ were replated in complete growth medium, and the number of attached cells was counted at the 6-hour time point. The data are expressed as a percentage of re-attached cells and are shown as an average \pm SD from three independent experiments. Black, gray, blue, and green correspond to $0,10,20$, and $50 \mathrm{mmol} / \mathrm{L} \mathrm{NAC}$, respectively, which was the concentration of NAC in the culture medium before replating.

\section{NAC Prevented Cellular Responses Intrinsic to Retinal Detachment}

We recently reported that vitreal growth factors such as bFGF indirectly activated PDGFR $\alpha$ and triggered a number of cellular responses intrinsic to PVR, including contraction of collagen gels and proliferation of cells. ${ }^{21}$ Furthermore, bFGF increased the level of ROS, and antioxidants such as NAC prevented indirect activation of PDGFR $\alpha$ as well as subsequent cellular responses. ${ }^{21}$ Consequently, we tested if NAC was capable of preventing these cellular responses when cells were simultaneously stimulated with a rich mixture of growth factors and cytokines, ie, vitreous. F (null for all PDGFRs) and $\mathrm{F} \alpha \Delta \mathrm{x}$ cells were used because this pair had the three features necessary to interpret the results of these studies: (1) A matched pair of cells that did and did not express PDGFR $\alpha$ (necessary to observe PDGFR $\alpha$-dependent augmentation of cellular responses); (2) The PDGFR $\alpha$ must be altered (ie, truncated) such that it was not competent to undergo direct (ie, PDGF-dependent) activation (to avoid the contribution of autocrine activation of PDGFR $\alpha$ by PDGF-C that fibroblasts and RPEs secrete and activate ${ }^{16}$ ); and (3) Cells null for both pdgfr genes (this enabled observation of the introduced, truncated PDGFR $\alpha$ without the contribution of endogenous PDGFRs).

$F$ cells failed to contract in response to rabbit vitreous, whereas F $\alpha \Delta$ x cells responded robustly (Figure 3, A and B). This response disappeared when the $F \alpha \Delta x$ cells were pretreated with $10 \mathrm{mmol} / \mathrm{L}$ NAC (Figure 3). A dose re- sponse experiment revealed that $2.5 \mathrm{mmol} / \mathrm{L}$ was the minimum dose of NAC needed to prevent contraction (Supplemental Figure S1, see http://ajp.amjpathol.org). These results indicate that expression of PDGFR $\alpha$ greatly potentiated the ability of cells to contract collagen gels in response to vitreous, and defined the minimum dose of NAC necessary to prevent this event.

To address how NAC influenced other vitreous-driven cellular responses, we considered cell proliferation. We previously found that bFGF induced proliferation of $F$
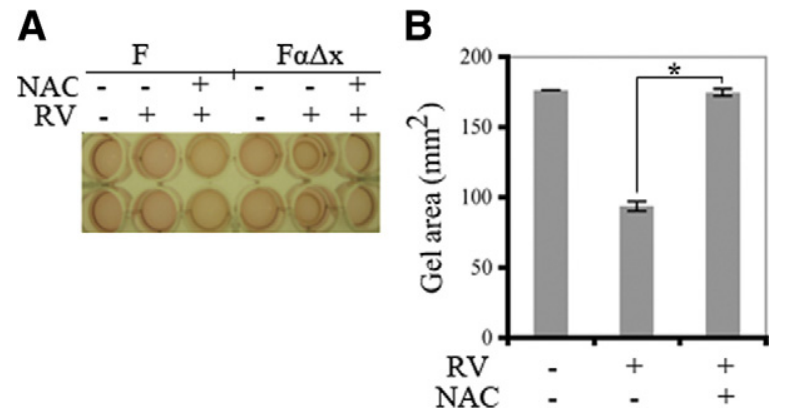

Figure 3. NAC prevented vitreous-dependent gel contraction. A: F and $\mathrm{F} \alpha \Delta \mathrm{x}$ cells were subjected to a collagen gel contraction assay in the presence or absence of $0.5 \mathrm{ml}$ vitreous from healthy rabbits (diluted 1:2 in DMEM). In some cases NAC $(10 \mathrm{mmol} / \mathrm{L})$ was also included. The picture shown is a representative experiment on day 3. B: The average \pm SD from three independent experiments; the width of the gel on day three was measured and the area was calculated $\left(\mathrm{a}=\pi r^{2}\right)$; there is a statistically significant difference, ${ }^{*} P<0.05$. The data show that expression of PDGFR $\alpha$ enabled cells to contract when exposed to vitreous and that NAC prevented this response. 


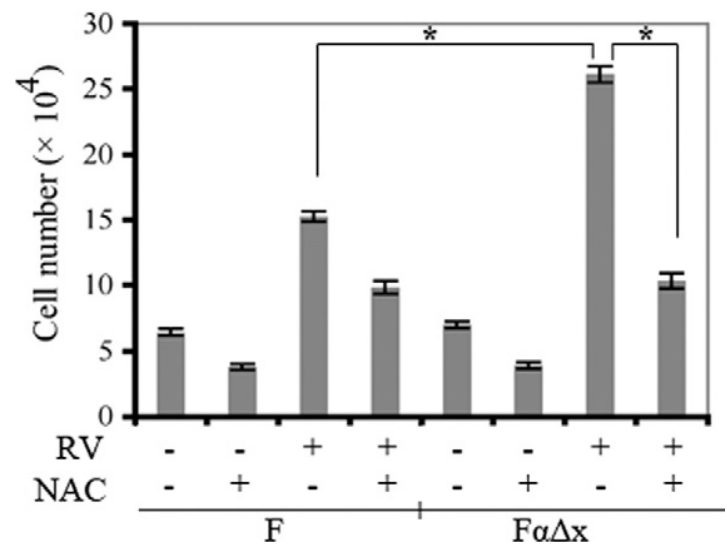

Figure 4. NAC blunted vitreous-driven proliferation. Cells were plated at a subconfluent density in serum-free medium that was supplemented with nothing, vitreous, or vitreous and NAC $(10 \mathrm{mmol} / \mathrm{L})$. Vitreous from healthy rabbits was diluted 1:2 in DMEM, and $0.5 \mathrm{ml}$ of the resulting solution was added to the appropriate wells of a 24 -well plate. The medium was replaced every day, and cells were counted on day three with a hemocytometer. The data shown are the mean $\pm \mathrm{SD}$ from three independent experiments; there is a statistically significant difference, ${ }^{*} P<0.05$. The data indicate that NAC blunted vitreous-driven proliferation of both cell lines and that the PDGFR $\alpha$ expressing cells lost their proliferative advantage in the presence of NAC.

cells, and that this bFGF-triggered response was greater for $\mathrm{F} \alpha \Delta \mathrm{x}$ as compared with $\mathrm{F}$ cells. ${ }^{21}$ Furthermore, the difference between the two cell types disappeared in the presence of NAC. ${ }^{21}$ Thus when exposed to single vitreal growth factor such as bFGF, PDGFR $\alpha$-expressing cells responded better than the same cells that did not express PDGFR $\alpha$. To test if this was also true in the more physiologically relevant setting, ie, when cells are exposed to vitreous that contains a complex mixture of growth factors, we repeated the experiment by using rabbit vitreous instead of bFGF. Vitreous promoted proliferation of both cell lines, and the response of the $F \alpha \Delta x$ line was greater than the F cells (Figure 4). Consistent with the finding that NAC attenuated serum-dependent proliferation of cells (Figure 2B), NAC blunted vitreousdependent proliferation in both cell lines. Importantly, $\mathrm{F} \alpha \Delta \mathrm{x}$ cells lost their proliferative advantage over $\mathrm{F}$ cells in the presence of NAC (Figure 4). A dose response experiment indicated that $2.5 \mathrm{mmol} / \mathrm{L} \mathrm{NAC}$ was the minimum dose required to eliminate the difference between the two cell lines (Supplemental Figure S2, see http://ajp. amjpathol.org). We conclude that expression of PDGFR $\alpha$ potentiated the ability of cells to proliferate in response to vitreous and that NAC effectively eliminated this advantage.

\section{NAC Protected Rabbits from Developing PVR}

Having identified the minimum effective dose and maximum tolerated dose of NAC for cells, we sought to establish the maximum dose of NAC that could be injected into the vitreous without overt retinal toxicity. To this end, we first performed a gas vitrectomy (to mimic the PVR protocol) and then injected a total of $0.1 \mathrm{ml}$ of NAC to achieve a final vitreal concentration of 2,10 , or 20 $\mathrm{mmol} / \mathrm{L}$. Two rabbits were injected with each of the three doses, and injections were repeated on day 2 and 4 (a

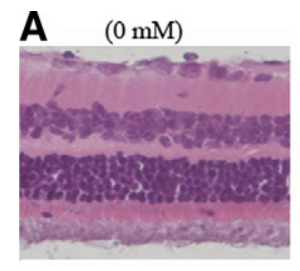

B $\quad(2 \mathrm{mM})$

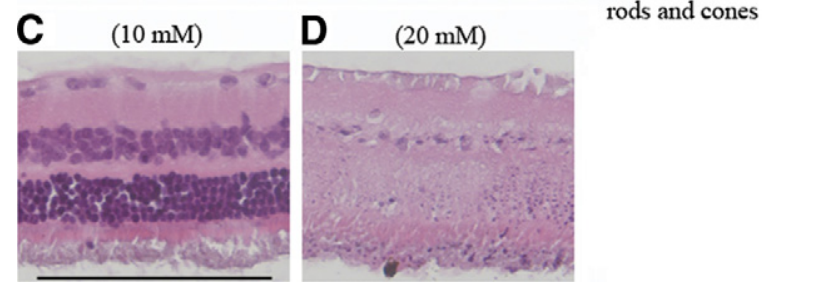

Figure 5. Histological analysis of retinas isolated from rabbits injected with increasing doses of NAC. Rabbits underwent a gas vitrectomy as described in Materials and Methods. One week after this procedure, $0.1 \mathrm{ml}$ of NAC was injected into vitreous to achieve a final vitreal concentration of 2,10 , or 20 $\mathrm{mmol} / \mathrm{L} \mathbf{B}, \mathbf{C}$, or $\mathbf{D}$, respectively. The NAC injection was repeated on days two and four. The rabbits underwent a fundus examination on days 1, 3, 5 , 7 , and 14 . After the last fundus examination, the rabbits were euthanized and the eyes were enucleated and fixed in $10 \%$ formalin. Sections were prepared, stained with hematoxylin and eosin, and photographed. Representative photos are presented in each panel, and the concentration of NAC is indicated. Scale bar $=100 \mu \mathrm{m}$

total of three injections). Although there were adverse effects (ie, retinal detachment) at the highest dose of $\mathrm{NAC}$, the two lower doses, 2 and $10 \mathrm{mmol} / \mathrm{L}$, were tolerated well. Histological analysis of retinas isolated from these animals confirmed these observations; only the high dose $(20 \mathrm{mmol} / \mathrm{L})$ of NAC induced overt retinal damage (Figure 5, A-D). Consequently, we chose the 10 $\mathrm{mmol} / \mathrm{L}$ dose for the subsequent experiments.

PVR was induced following our standard protocol of a gas vitrectomy followed by injection of cells (in this case $\mathrm{F} \alpha \Delta \mathrm{x}$ ) and platelet-rich plasma. To test whether NAC could prevent PVR, we modified the PVR protocol to include injection on days $0,2,4$, and 7 of $0.1 \mathrm{ml}$ of buffer (DMEM) or $100 \mathrm{mmol} / \mathrm{L}$ of NAC in DMEM (to achieve a final vitreal concentration of $10 \mathrm{mmol} / \mathrm{L}$ ). As shown in Figure 6A, control rabbits (injected with the buffer) developed PVR over the course of the 4-week experiment. The response was significantly reduced in rabbits injected with NAC, and the suppression of the response persisted for 3 weeks after cessation of NAC injections (Figure 6A). Furthermore, although most of the NAC-treated rabbits developed membranes, none of them progressed to retinal detachment (Figure 6A). Representative fundus photos of each stage of PVR and histological sections of a retina with and without a PVR membrane are presented in Supplemental Figure S3 at http://ajp.amjpathol.org. These studies indicate that NAC effectively protected rabbits from developing the site-robbing phase of PVR.

Although NAC therapy effectively protected rabbits from retinal detachment, most of the rabbits treated with NAC still developed membranes (stage 1 and 2), which suggests that NAC did not compromise the ability of the injected cells to survive. Indeed, Western blot analysis of PVR membranes isolated from the two experimental groups revealed a comparable amount of PDGFR $\alpha \Delta \mathrm{X}$ (arrowhead in the lower panel of Figure 6B). There was 

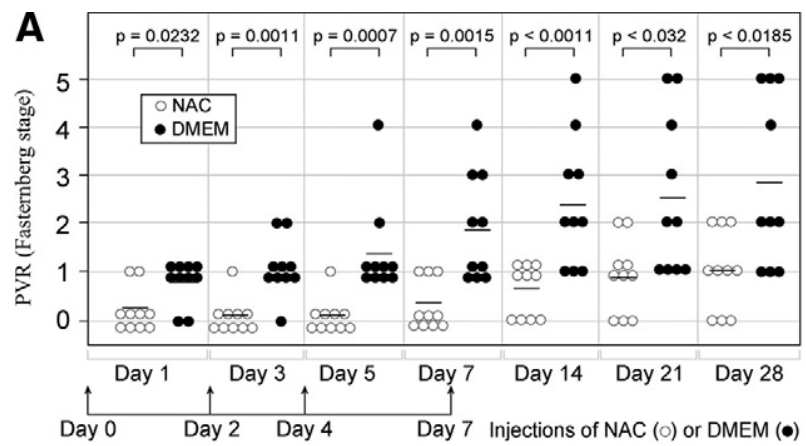

B

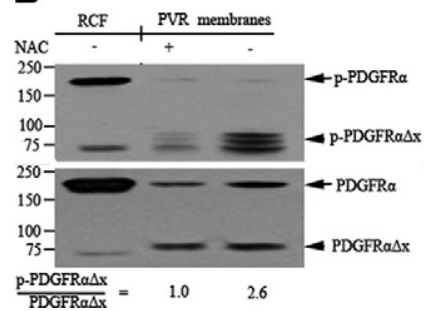

C

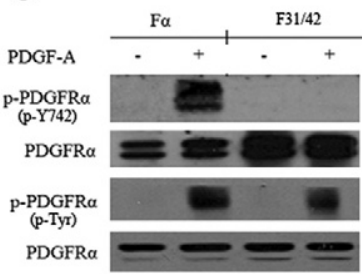

Figure 6. NAC therapy blunted in vivo activation of PDGFR $\alpha$ and prevented retinal detachment. A: One week after a gas vitrectomy, rabbits were intravitreally injected with platelet-rich plasma and $\mathrm{F} \alpha \Delta \mathrm{x}$ cells. All rabbits also received $0.1 \mathrm{ml}$ injections of either buffer (DMEM) or NAC $(100 \mathrm{mmol} / \mathrm{L}$ in DMEM) on days $0,2,4$, and 7 . The rabbits were examined at the indicated times, and the PVR status for each rabbit was plotted. The horizontal bar is the mean of each group. The data were subjected to Mann-Whitney analysis to assess whether there were statistically significant differences between these two groups. The $P$ value is indicated at the top of the figure. The data reveal that NAC prevented rabbits from developing retinal detachment. B: Once the animals were sacrificed (on day 28), the eyes were enucleated and PVR membranes were harvested from four eyes with the most severe PVR in each experimental group: stages one and two for the NAC-treated group stages four and five for the DMEM-treated group. The membranes within each group were pooled, homogenized in sample buffer, and subjected to Western blotting using an antibody against phospho-PDGFR $\alpha$ Y 742 (top panel). The membrane was stripped and reprobed using a pan PDGFR $\alpha$ antibody (number 3164 from Cell Signaling; bottom panel). Numbers on the left indicate molecular weight (kilodalton). Normalization of the phosphosignal by the amount of PDGFR $\alpha$ present indicated that NAC reduced phosphorylation of PDGFR $\alpha \Delta \mathrm{x}$ by 2.6-fold. The left lane contains RCFs and is included as a positive control. C: F $\alpha$ (F cells expressing wild-type PDGFR $\alpha^{18}$ ) or F31/42 (F cells expressing a PDGFR $\alpha$ mutant in which tyr at 731 and 742 are mutated to phe $\mathrm{p}^{22}$ ) were stimulated with PDGF-A $(50 \mathrm{ng} / \mathrm{ml})$ for 10 minutes and then lysed. In the top panel, cleared cell lysate was subjected to Western blot analysis using a phospho-Y742 PDGFR $\alpha$ antibody (upper half); the blot was stripped and subsequently probed with a pan-PDGFR $\alpha$ antibody (27P; lower half). In the bottom panel PDGFR $\alpha$ immunoprecipitates were subjected to Western blot analysis using an anti-phosphotyrosine antibody (upper half); the blot was stripped and subsequently probed with a pan-PDGFR $\alpha$ antibody (27P; lower half). The data indicate that recognition of phosphorylated PDGFR $\alpha$ by the phospho-Y742 antibody is dependent on either tyr 731 or 742 (presumably 742 ). The results were representative of two independent experiments.

slightly more full-length PDGFR $\alpha$ in membranes isolated from control rabbits (arrow in lower panel of Figure 6B), perhaps because membranes isolated from rabbits with advanced stages of PVR have more rabbit-derived tissue (which expressed full-length PDGFR $\alpha$ ) associated with it.

To test if NAC prevented activation of PDGFR $\alpha$ in vivo, we assessed the extent of PDGFR $\alpha$ phosphorylation in PVR membranes by using a phosphospecific antibody that recognized activated PDGFR $\alpha$ (Figure 6C). ${ }^{18,22}$ When normalized for the amount of PDGFR $\alpha$, there was 2.6-fold greater phosphorylation of PDGFR $\alpha \Delta \mathrm{X}$ in membranes isolated from the control rabbits, as compared with those injected with NAC (arrowhead in the upper
A

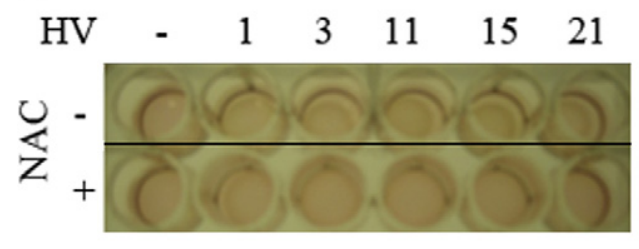

B

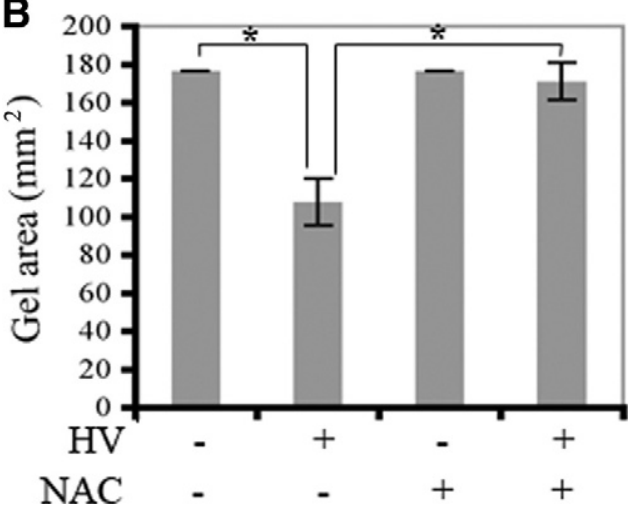

Figure 7. NAC prevented patient vitreous-driven contraction. A: Primary human RPE cells that were obtained from a clinical PVR membrane were subjected to the collagen contraction assay. Vitreous from PVR patient donors $(100 \mu \mathrm{l})$ was added together with $400 \mu \mathrm{l}$ DMEM on top of the gel to promote contraction. Some of the wells also received NAC (final concentration of $10 \mathrm{mmol} / \mathrm{L}$ ). The photograph was taken on day three. The numbers at the top of $\mathbf{A}$ indicate the different patients. B: The gel area was calculated, and the data from all five patients were pooled and presented as the mean \pm $\mathrm{SD}$; there is a statistically significant difference, ${ }^{*} P<0.05$. The data indicate that patient vitreous induced contraction of cells that were isolated from a clinical PVR membrane and that NAC effectively blocked this response.

panel of Figure 6B). We conclude that although NAC did not compromise the viability of the injected cells, it suppressed both receptor phosphorylation/activation and retinal detachment.

\section{NAC Suppressed Patient-Driven Contraction of Collagen Gels Containing RPE Cells}

We performed the following experiments to begin to address if NAC was likely to prevent contraction of PVR membranes in the clinical setting. Primary RPE cells isolated from a human PVR membrane were subjected to the collagen gel contraction assay. In these experiments we used vitreous from five PVR patient donors to induce contraction. As shown in Figure 7, A and B, vitreous from all patients promoted contraction of the RPE-containing gel. Furthermore, NAC prevented this response in all cases. These results show that NAC prevented patient vitreous-driven contraction of cells isolated from a human PVR membrane, and thereby suggest that NAC has the potential to prevent retinal detachment in PVR patients.

\section{Discussion}

In this study we tested the hypothesis that an anti-oxidant used in various nonophthalmologic settings would protect rabbits from retinal detachment in our PVR model. We found that the minimum effective dose that prevented 
all PDGFR $\alpha$-dependent cellular and biochemical events was $2.5 \mathrm{mmol} / \mathrm{L}$, whereas the maximum intravitreally delivered dose that caused no overt retinal toxicity was 10 $\mathrm{mmol} / \mathrm{L}$. Furthermore, the $10 \mathrm{mmol} / \mathrm{L}$ dose of NAC suppressed activation of PDGFR $\alpha$ and protected rabbits from progressing to the sight-robbing phase of PVR, retinal detachment. Finally, NAC prevented patient vitreous-driven contraction of cells isolated from a human epiretinal membrane. We conclude that NAC protected rabbits from experimental PVR and may be effective in patients.

Although NAC blocked retinal detachment, it did not prevent the formation of an epiretinal membrane (Figure $6 \mathrm{~A}$ ). Because PDGFR $\alpha$ expressed by the injected cells was not activate-able by PDGF, and NAC blocked indirect activation of PDGFR $\alpha$, it seems likely that vitreal growth factors acted independently of PDGFR $\alpha$ to promote the formation of the membrane. Indeed, cells that have no PDGFRs still form membranes in this model. ${ }^{18}$ Connective tissue growth factor, which is present in the vitreous and promotes formation of an epiretinal membrane in animal models of PVR, is likely to be a contributor. ${ }^{29,30}$

It remains an open question of whether membrane formation requires proliferation of cells for experimental PVR to develop. Irradiated cells, which are unable to proliferate, are capable of inducing PVR, provided that a sufficient number of them are injected. ${ }^{31}$ Simply surviving, generating extracellular matrix proteins, and contracting the resulting membrane may be sufficient for retinal detachment/PVR. If this is indeed the case, then this model of PVR underestimates the therapeutic potential of NAC because it limits cell proliferation, especially when dependent on PDGFR $\alpha$ (Figures 2, A and B, and 4).

Future investigation is necessary to address the clinical applicability of NAC. For instance, pharmacological studies should focus on refining and potentially reducing the administration schedule of NAC. Oral administration should also be considered, provided that it is coupled with a suitable approach to measure the concentration of NAC in the vitreous. It would be informative to learn if NAC is effective in additional models of retinal detachment and how NAC compares with other anti-oxidants. Finally, anti-oxidants therapy should be considered in combination with other therapeutic approaches.

In conclusion, our previous efforts to elucidate the signaling/biochemical events that are required for PVR led to identification of several potential therapeutic targets. The initial attempts to test one of them (NAC) are encouraging and suggest that antioxidants may be a new approach to protect patients undergoing retinal surgery from developing detachments.

\section{Acknowledgments}

We thank Marie Ortega and Jessica Lanzim for their help with the animal studies, Peter Mallen for assistance with preparing figures, and Bianai Fan for histological sections.

\section{References}

1. Campochiaro PA: Pathogenic mechanisms in proliferative vitreoretinopathy. Arch Ophthalmol 1997, 115:237-241

2. Glaser BM, Cardin A, Biscoe B: Proliferative vitreoretinopathy: the mechanism of development of vitreoretinal traction. Ophthalmology 1987, 94:327-332

3. Charteris DG: Growth factors in proliferative vitreoretinopathy. Br J Ophthalmol 1998, 82:106

4. Laqua H, Machemer R: Glial cell proliferation in retinal detachment (massive periretinal proliferation). Am J Ophthalmol 1975, 80: 602-618

5. Ryan SJ: Traction retinal detachment. XLIX Edward Jackson Memorial Lecture. Am J Ophthalmol 1993, 115:1-20

6. Blumenkranz MS, Ophir A, Claflin AJ, Hajek A: Fluorouracil for the treatment of massive periretinal proliferation. Am J Ophthalmol 1982 $94: 458-467$

7. Wiedemann P, Lemmen K, Schmiedl R, Heimann K: Intraocular daunorubicin for the treatment and prophylaxis of traumatic proliferative vitreoretinopathy. Am J Ophthalmol 1987, 104:10-14

8. Wiedemann P, Sorgente N, Bekhor C, Patterson R, Tran T, Ryan SJ: Daunomycin in the treatment of experimental proliferative vitreoretinopathy: effective doses in vitro and in vivo. Invest Ophthalmol Vis Sci 1985, 26:719-725

9. Wu PC, Tai MH, Hu DN, Lai CH, Chen YH, Wu YC, Tsai CL, Shin SJ, Kuo HK: Cyclin-dependent kinase inhibitor roscovitine induces cell cycle arrest and apoptosis in rabbit retinal pigment epithelial cells. J Ocul Pharmacol Ther 2008, 24:25-33

10. Falkenstein IA, Cheng L, Wong-Staal F, Tammewar AM, Barron EC, Silva GA, Li QX, Yu D, Hysell M, Liu G, Ke N, Macdonald JE, Freeman WR: Toxicity and intraocular properties of a novel long-acting antiproliferative and anti-angiogenic compound IMS2186. Curr Eye Res 2008, 33:599-609

11. Kim IK, Arroyo JG: Mechanisms in proliferative vitreoretinopathy. Ophthalmol Clin North Am 2002, 15:81-86

12. Murata T, Kimura H, Sakamoto T, Osusky R, Spee C, Stout TJ, Hinton DR, Ryan SJ: Ocular gene therapy: experimental studies and clinical possibilities. Ophthalmic Res 1997, 29:242-251

13. Chang YC, Hu DN, Wu WC: Effect of oral 13-cis-retinoic acid treatment on postoperative clinical outcome of eyes with proliferative vitreoretinopathy. Am J Ophthalmol 2008, 146:440-446

14. Menon G, Walters G: New paradigms in the treatment of wet AMD: the impact of anti-VEGF therapy. Eye 2009, 23 Suppl 1:S1-S7

15. Hochhaus A: Imatinib mesylate (Glivec, Gleevec) in the treatment of chronic myelogenous leukemia $(\mathrm{CML})$ and gastrointestinal stromal tumors (GIST). Ann Hematol 2004, 83 Suppl 1:S65-S66

16. Lei H, Hovland P, Velez G, Haran A, Gilbertson D, Hirose T, Kazlauskas A: A potential role for PDGF-C in experimental and clinical proliferative vitreoretinopathy. Invest Ophthalmol Vis Sci 2007, 48:2335-2342

17. Cui J, Lei H, Samad A, Basavanthappa S, Maberley D, Matsubara J, Kazlauskas A: PDGF receptors are activated in human epiretinal membranes. Exp Eye Res 2009, 88:438-444

18. Andrews A, Balciunaite E, Leong FL, Tallquist M, Soriano P, Refojo M, Kazlauskas A: Platelet-derived growth factor plays a key role in proliferative vitreoretinopathy. Invest Ophthalmol Vis Sci 1999, 40:2683-2689

19. Ikuno Y, Leong FL, Kazlauskas A: Attenuation of experimental proliferative vitreoretinopathy by inhibiting the platelet-derived growth factor receptor. Invest Ophthalmol Vis Sci 2000, 41:3107-3116

20. Ikuno $Y$, Kazlauskas A: An in vivo gene therapy approach for experimental proliferative vitreoretinopathy using the truncated plateletderived growth factor alpha receptor. Invest Ophthalmol Vis Sci 2002, 43:2406-2411

21. Lei $H$, Kazlauskas A: Growth factors outside of the PDGF family employ ROS/SFKs to activate PDGF receptor alpha and thereby promote proliferation and survival of cells. J Biol Chem 2009, 284:6329-6336

22. Rosenkranz S, DeMali KA, Gelderloos JA, Bazenet C, Kazlauskas A: Identification of the receptor-associated signaling enzymes that are required for platelet-derived growth factor-AA-dependent chemotaxis and DNA synthesis. J Biol Chem 1999, 274:28335-28343 
23. Nakagawa M, Refojo MF, Marin JF, Doi M, Tolentino FI: Retinoic acid in silicone and silicone-fluorosilicone copolymer oils in a rabbit model of proliferative vitreoretinopathy. Invest Ophthalmol Vis Sci 1995, 36:2388-2395

24. Wong CA, Potter MJ, Cui JZ, Chang TS, Ma P, Maberley AL, Ross WH, White VA, Samad A, Jia W, Hornan D, Matsubara JA: Induction of proliferative vitreoretinopathy by a unique line of human retinal pigment epithelial cells. Can J Ophthalmol 2002, 37:211-220

25. Gelderloos JA, Rosenkranz S, Bazenet C, Kazlauskas A: A role for Src in signal relay by the platelet-derived growth factor alpha receptor. J Biol Chem 1998, 273:5908-5915

26. Maberley D, Cui JZ, Matsubara JA: Vitreous leptin levels in retinal disease. Eye 2006, 20:801-804

27. Heeneman S, Haendeler J, Saito Y, Ishida M, Berk BC: Angiotensin II induces transactivation of two different populations of the platelet- derived growth factor beta receptor: key role for the p66 adaptor protein Shc. J Biol Chem 2000, 275:15926-15932

28. Sundaresan M, Yu ZX, Ferrans VJ, Irani K, Finkel T: Requirement for generation of $\mathrm{H} 2 \mathrm{O} 2$ for platelet-derived growth factor signal transduction. Science 1995, 270:296-299

29. He S, Chen Y, Khankan R, Barron E, Burton R, Zhu D, Ryan SJ, Oliver N, Hinton DR: Connective tissue growth factor as a mediator of intraocular fibrosis. Invest Ophthalmol Vis Sci 2008, 49:4078- 4088

30. Abu El-Asrar AM, Van den Steen PE, Al-Amro SA, Missotten L, Opdenakker G, Geboes K: Expression of angiogenic and fibrogenic factors in proliferative vitreoretinal disorders. Int Ophthalmol 2007 27:11-22

31. Fastenberg DM, Diddie KR, Sorgente N, Ryan SJ: A comparison of different cellular inocula in an experimental model of massive periretinal proliferation. Am J Ophthalmol 1982, 93:559-564 